\title{
Prenatal Detection of Embryo Resorption in Osteopontin-Deficient Mice Using Serial Noninvasive Magnetic Resonance Microscopy
}

\author{
ANDREA S. WEINTRAUB, XINJIE LIN, VITALII V. ITSKOVICH, J. GILBERTO S. AGUINALDO, \\ WILLIAM F. CHAPLIN, DAVID T. DENHARDT, AND ZAHI A. FAYAD \\ Department of Pediatrics [A.S.W.], The Mount Sinai School of Medicine, New York, New York 10029, \\ U.S.A.; Department of Chemical Biology [X.L.], Rutgers University, Piscataway, New Jersey 08854, \\ U.S.A.; Imaging Sciences Laboratories [V.V.I., J.G.S.A., Z.A.F.], Department of Radiology [V.V.I., Z.A.F.], \\ The Zena and Michael A. Wiener Cardiovascular Institute and the Marie-Josée and Henry R. Kravis \\ Cardiovascular Health Center [J.G.S.A., Z.A.F.], Department of Medicine, The Mount Sinai School of \\ Medicine, New York, New York 10021, U.S.A.; Department of Psychology [W.F.C.], St. John's University, \\ Jamaica, New York 11439, U.S.A.; and the Department of Cell Biology and Neuroscience [D.T.D.], \\ Rutgers University, Piscataway, New Jersey 08854, U.S.A.
}

\begin{abstract}
Appropriate temporal and spatial expression of osteopontin (OPN) in the female genital tract may be critical for successful embryo implantation and maintenance of gestation. Traditionally, experimental assessments of reproductive success have been limited to ex vivo dissection at a single time point to determine embryo number and size and are inadequate for ongoing study of the effect(s) of genetic manipulation on any individual gestation. To investigate the role of OPN in the maintenance of gestation, we developed a noninvasive, in vivo method of pregnancy surveillance suitable for murine application using magnetic resonance microscopy (MRM). Gravid wild-type mice $(n=7)$ and mice with targeted disruption of one or both OPN alleles $\left(\mathrm{OPN}^{-/-}, n=9\right.$; $\left.\mathrm{OPN}^{+/-}, n=3\right)$ underwent MRM on postcoital days $10.5,15.5$, and 19.5. Prenatal MRM images were used
\end{abstract}

\section{ABSTRACT}

to determine embryo numbers and sizes. There were no significant differences in embryo numbers determined independently by two blinded observers (mean difference between observers = 0.04 embryos; $p=0.87$ ). There was a significant effect of genotype on embryo size, with $\mathrm{OPN}^{-1-}$ embryos significantly smaller at all gestational ages. However, targeted disruption of one or more OPN alleles had no effect on embryo number at any gestational age. Thus, MRM may be a powerful noninvasive method for in vivo prenatal developmental study of genetically engineered mice. (Pediatr Res 55: 419-424, 2004)

OPN, osteopontin

\section{Abbreviations}

MRM, magnetic resonance microscopy
Osteopontin (OPN) is a secreted matrix protein with an RGD-binding motif that interacts with multiple integrins (1-3). Through these interactions, OPN modulates cell adhesion and transduces intracellular signals that mediate cell proliferation, differentiation, invasion, migration, and survival (4-8). OPN also plays a significant role in host immune responses as a proinflammatory cytokine and macrophage and T-cell chemoattractant $(4,9-13)$. In healthy mammals, OPN is found in

Received May 28, 2003; accepted November 12, 2003.

Correspondence: Andrea S. Weintraub, M.D., The Mount Sinai School of Medicine, Box 1508, One Gustave L. Levy Place, New York, NY 10029, U.S.A.; e-mail: andrea.weintraub@mssm.edu

Supported by Mentored Clinician Scientist Award HL-3508 from the National Heart, Lung, and Blood Institute (ASW) and a Howard Hughes Medical Institute Biomedical Research Support Program Grant (ZAF, VVI).

Part of this work was presented at the 2002 Annual Meeting of the Society for Pediatric Research in Baltimore, MD, U.S.A.

DOI: 10.1203/01.PDR.0000112034.98387.B2 a relatively restricted tissue distribution and is constitutively expressed at low levels in most epithelial-lining cells (11, 14-16). OPN expression is strikingly up-regulated under conditions of inflammation and tissue remodeling (4, 11, 17-19).

Much has been discerned about the biologic function of OPN through the study of $\mathrm{OPN}^{-1-}$ mice. $\mathrm{OPN}^{-1-}$ mice display no specific phenotype under normal colony conditions, but OPN deficiency is associated with 1) defective macrophage accumulation at sites of tissue injury, 2) abnormal cellmediated immunity to Herpes simplex-1 and Listeria monocytogenes, 3) disseminated Mycobacterium bovis BCG infection and a poor granulomatous response, and 4) a delayed granulomatous response in a Schistosoma mansoni egg pulmonary granuloma model $(9,13,20-22)$. There is an expanding literature on the biologic role of OPN in cancer, cardiovascular disease, multiple sclerosis, renal tubulointerstitial fibrosis, and 
granulomatous diseases $(3,19,23-26)$. The role of OPN in reproduction, however, has been largely unexplored.

There is circumstantial evidence to suggest that OPN may play an important role in mammalian reproduction. OPN expression in the reproductive tracts and placentas of many species has been well-established. In nongravid mice, rabbits, sheep, pigs, primates, and humans, OPN protein is expressed by the uterine luminal epithelium during the secretory phase of the estrous or menstrual cycle $(15,16,27-31)$. This positions OPN spatially and temporally to participate in key integrinmediated adhesive interactions of implantation, should fertilization occur. After conception, OPN is expressed by cells in the decidualizing uterine stroma, as well as by invading trophoblasts, and by specialized endometrial immune cells (16, $32,33)$. This further positions OPN to participate in critical interactions at the maternal-fetal interface. OPN induces Th1 and inhibits Th2 cytokine expression, directly stimulates IL-12 production by murine macrophages, and inhibits IL-10 production by lipopolysaccharide-stimulated macrophages $(4,13)$. Although the Th1 cytokine profile is generally not thought to be beneficial for the fetus, it has been suggested that OPNinduced Th1 responses may protect the developing embryo from infectious pathogens introduced during mating (29). Therefore, a role for OPN in the initiation of implantation and maintenance of pregnancy could be postulated.

To explore this hypothesis, we sought a noninvasive method of pregnancy surveillance suitable for murine application. Traditionally, experimental assessments of embryo number and size have been limited to ex vivo examinations at a single time point and thus are inadequate for ongoing study of the effect(s) of genetic manipulation on any individual gestation. We present herein a noninvasive, in vivo method of serial pregnancy surveillance using magnetic resonance microscopy (MRM) that was developed to investigate the role of OPN in the maintenance of murine gestation. MRM is a noninvasive, nondestructive, three-dimensional imaging technique that differentiates tissue structure on the basis of proton magnetic properties and allows a wide range of image contrast (34). Small structures, such as early mouse embryos and placentas, can be imaged with the use of high-magnetic-field systems $(>1.5$ Tesla) equipped with small radiofrequency coils and strong magnetic field gradients (35). Previously, the application of this technology to rodent reproduction was limited to studies of embryonic development using fixed embryos inside (36) or outside the uterus (37-39) and to studies of toxicity and teratogenicity $(40-42)$, with the exception of one report of MRM used to investigate rat embryo development in vivo (43). Here, to the best of our knowledge, we present the first serial in vivo MRM images of murine gestation that noninvasively identify prenatal embryo resorption.

\section{METHODS}

Animals. OPN ${ }^{-1-}$ mice with a C57B1/129Sv background were generated by Rittling et al. (20). $\mathrm{OPN}^{+/+} \times \mathrm{OPN}^{+/+}$, $\mathrm{OPN}^{-1-} \times \mathrm{OPN}^{-1-}$, and $\mathrm{OPN}^{+/} \times \mathrm{OPN}^{+/-}$matings were used to create the colony of mice used in the experiments described herein. The genotypes of all mice were confirmed by
Southern blot analysis. Animals were housed in the Center for Laboratory Animal Science at the Mount Sinai School of Medicine (New York, NY, U.S.A.). Procedures and animal care were approved by the Institutional Animal Care and Use Committee and were in accordance with the Guide for the Care and Use of Laboratory Animals. Mice were weaned at 4 wk of age and fed standard rodent chow (PMI Nutrition International, St. Louis, MO, U.S.A.) and water ad libitum. The mice used for the experiments described herein were 6-9 mo of age.

Histology. Homozygous breeding pairs $\left(\mathrm{OPN}^{+/+} \times\right.$ $\mathrm{OPN}^{+/+}, \mathrm{OPN}^{-/-} \times \mathrm{OPN}^{-/-}$, and $\left.\mathrm{OPN}^{+/-} \times \mathrm{OPN}^{+/-}\right)$were allowed to cohabitate overnight. Female mice were examined the following morning to verify the presence of a copulatory plug. OPN ${ }^{+/+}(n=18), \mathrm{OPN}^{-/-}(n=19)$, and $\mathrm{OPN}^{+/-}(n$ $=10)$ female mice with verified copulatory plugs were killed and dissected at $10.5 \mathrm{~d}$ postcoitus to compare the incidence of pregnancy across genotypes. Mice were killed by exsanguination under deep anesthesia and perfused with PBS followed by 10\% sucrose/Tissue-tek (Sakura Finetek USA Inc., Torrance, CA, U.S.A.). Uteri and their contents were excised en bloc, examined grossly to determine the number of embryos in each uterine horn, infiltrated with sucrose solutions of increasing concentration, and snap-frozen in liquid nitrogen. Frozen sections $(6 \mu \mathrm{m})$ through the embryo and placenta at the implantation site were stained with hematoxylin and eosin.

In vivo MRM. A small pilot imaging study during early gestation (6.5-10.5 d postcoitus) suggested that $10.5 \mathrm{~d}$ was the lower limit of gestation when embryos could be reliably identified using this technique, mainly as a result of the available spatial resolution. For the experiments described herein, homozygous breeding pairs $\left(\mathrm{OPN}^{+/+} \times \mathrm{OPN}^{+/+}, \mathrm{OPN}^{-/-} \times\right.$ $\mathrm{OPN}^{-/-}$, and $\mathrm{OPN}^{+/-} \times \mathrm{OPN}^{+/-}$) were allowed to cohabitate overnight. Female mice were examined the following morning to verify the presence of a copulatory plug. If a plug was identified, then the female underwent MRM on postcoital days $10.5,15.5$, and 19.5. For each genotype $\left(\mathrm{OPN}^{+/+}, \mathrm{OPN}^{-/-}\right.$, and $\mathrm{OPN}^{+-}$), three groups of mice were studied on each imaging day: 1) mice that were anesthetized and underwent MRM; 2) mice that received only anesthesia; and 3) mice that were exposed to the acoustic, lighting, and temperature stimuli of the imaging room but were not anesthetized, restrained, or placed in the MR system.

Mice were anesthetized with isoflurane $/ \mathrm{O}_{2}$ at $4 \%$ and maintained at $1.5 \%$ volume. Each mouse was placed in a $30-\mathrm{mm}$ birdcage transmit/receive coil within an animal handling system. A respiratory sensor was placed on the abdomen for triggering and for monitoring the depth and the frequency of respiration. The sensor was connected to a Physioguard SM 785 NMR triggering unit (Bruker Instruments, Billerica, MA, U.S.A.). After imaging, mice were returned to their cages and allowed to recover completely from anesthesia under heating lamps before being returned to the animal facility. The duration of anesthesia averaged 3-3.5 h.

In vivo MRM was performed with a Bruker AVANCE 9.4T, 89-mm bore magnet system operating at a proton frequency of $400 \mathrm{MHz}$ (Bruker). An in vivo probe (Micro 2.5) was used in combination with a gradient system of $1000 \mathrm{mT} / \mathrm{m}$ and a rise time of $110 \mu \mathrm{s}$. The software package used for data acquisition 
and initial processing was Paravision 2.1 (Bruker) on a Silicon Graphics $\mathrm{O}_{2}$ workstation with an Irix 6.5 operating system. The total imaging time for each experiment was approximately $2 \mathrm{~h}$. Imaging began with a gradient echo scout sequence for position determination. Three orthogonal slices were acquired to obtain sagittal, axial, and coronal views. Subsequent pulse sequences were multislice spin-echo with parameters for proton density weighted images and fat suppression. The repetition time and echo time were $2000 \mathrm{~ms}$ and $10 \mathrm{~ms}$, respectively, for the proton density weighted pulse sequence. Twelve 1-mmthick slices were acquired for coronal (contiguous slices) and axial views (interslice distance $0.5 \mathrm{~mm}$ ). The matrix size was $256 \times 256$ pixels, with a typical field of $35 \times 35 \mathrm{~mm}$ (corresponding to a pixel size of $137 \mu \mathrm{m}$ ).

Hard copies of the MRM images were interpreted independently by two investigators (A.S.W. and J.G.A.) who were blinded to each other's observations. Each investigator recorded the total number of embryos that he or she counted in each dam on days $10.5,15.5$, and 19.5 postcoitus. Both interobserver reliability (the degree to which the two investigators agreed about the number of embryos seen in each dam at each gestational age) and observer validity (the extent to which the two investigators' observations accurately reflected the actual number of embryos) were assessed to determine the utility of MRM as a technique for the identification and monitoring of prenatal embryo resorption. Embryo size was determined through calculation of the maximal cross-sectional area [shortaxis $(\mathrm{mm}) \times$ long-axis $(\mathrm{mm}) \times \pi]$.

Statistical analyses. For the histologic study, the Fisher exact test was used to compare the incidence of pregnancy across genotypes at $10.5 \mathrm{~d}$ postcoitus. For the MRM studies, the number of embryos counted per dam by each of the two observers on days $10.5,15.5$, and 19.5 postcoitus were compared using a paired $t$ test. Statistical significance was considered at the level $p<0.05$. This analysis revealed no statistically significant differences between the two investigators' counts (see "Results"); therefore, the values of the two observers for each dam on each imaging day were averaged, and that average was defined (for the purposes of this report) as the "embryo count" for that dam on that day. This embryo count was analyzed across genotype and gestational day of imaging using a two-way ANOVA, with individual points compared by the least significant difference test (44). The validity of MRM was determined by comparing the late gestation (19.5 day postcoitus) embryo count for each dam with her actual litter size. Embryo sizes for $\mathrm{OPN}^{+/+}$and $\mathrm{OPN}^{-/-}$dams were compared on days $10.5,15.5$, and 19.5 using a two-way ANOVA. For normally distributed variables, data are expressed as mean $\pm \mathrm{SEM}$; for data that are not normally distributed, data are expressed as median (range 25-75\%).

\section{RESULTS}

We compared the incidence of pregnancy in wild-type $\left(\mathrm{OPN}^{+/+}\right)$mice with that of mice with a targeted disruption of at least one OPN allele $\left(\mathrm{OPN}^{-/-}\right.$and $\left.\mathrm{OPN}^{+/-}\right)$. Through ex vivo dissection on day 10.5 postcoitus, it was demonstrated that $72 \%$ of $\mathrm{OPN}^{+/+}$female mice with a verified copulatory plug were indeed gravid, with more than one embryo identified. Surprising, however, is that only $37 \%$ of $\mathrm{OPN}^{-1-}$ female mice and $40 \%$ of $\mathrm{OPN}^{+-}$female mice with identified plugs were found to be pregnant ( $p<0.05$, Fisher exact test; Fig. 1). On the basis of this observation, we hypothesized that disruption of the OPN gene results in an incompletely penetrant, "all-ornothing" effect on murine gestation that compromises reproductive success by interfering with conception, implantation, or the maintenance of gestation.

To explore this hypothesis further, we developed and used serial in vivo MRM as a noninvasive prenatal method of monitoring embryos (both numbers and sizes) throughout murine gestation. $\mathrm{OPN}^{+/+}(n=7), \mathrm{OPN}^{-/-}(n=9)$, and $\mathrm{OPN}^{+/-}$ $(n=3)$ female mice with verified copulatory plugs underwent MRM at 10.5, 15.5, and $19.5 \mathrm{~d}$ postcoitus. There were no significant differences in mortality for dams or their pups in the MRM and control groups. Examination of pups within the first $48 \mathrm{~h}$ of life revealed no gross physical abnormalities in either the MRM or the control groups. Representative coronal MRM images of gravid $\mathrm{OPN}^{+/+}$female mice are shown in Figure 2.

MRM images were interpreted independently by two investigators (A.S.W. and J.G.A.) who were blinded to each other's observations; each investigator recorded the total number of embryos that he or she counted in each dam on 10.5, 15.5, and $19.5 \mathrm{~d}$ postcoitus. There was no statistically significant difference between the two investigators' counts (mean difference \pm SEM $=0.04 \pm 0.25$ embryos; $p=0.87$ ). Therefore, the values of the two observers for each dam on each imaging day were averaged, and that average was defined as the embryo count for that dam on that day.

The mean embryo count \pm SD for dams of each genotype (white bars: $\mathrm{OPN}^{+/+}$; black bars: $\mathrm{OPN}^{-/-}$; stippled bars: $\left.\mathrm{OPN}^{+/-}\right)$at the four times of measurement $(10.5 \mathrm{~d}, 15.5 \mathrm{~d}$, $19.5 \mathrm{~d}$, and birth) are shown in Figure 3. The two-way ANOVA showed a statistically significant effect of gestational age on embryo count $(p<0.001)$, with no effect of genotype

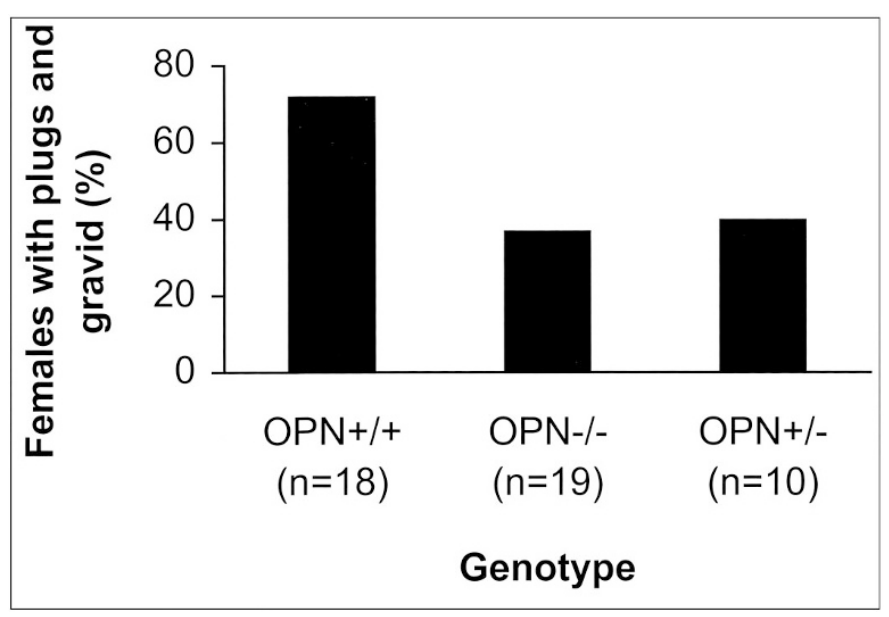

Figure 1. Ex vivo determination of incidence of pregnancy. $\mathrm{OPN}^{+/+}$, $\mathrm{OPN}^{-1-}$, and $\mathrm{OPN}^{+/-}$female mice with verified copulatory plugs were killed at $10.5 \mathrm{~d}$ postcoitus to compare the incidence of pregnancy across genotypes. For each genotype, the black bars indicate the percentage of mice with detectable vaginal plugs that were also found to be gravid upon dissection. Pregnancy rates across genotypes were compared using the Fisher exact test. 

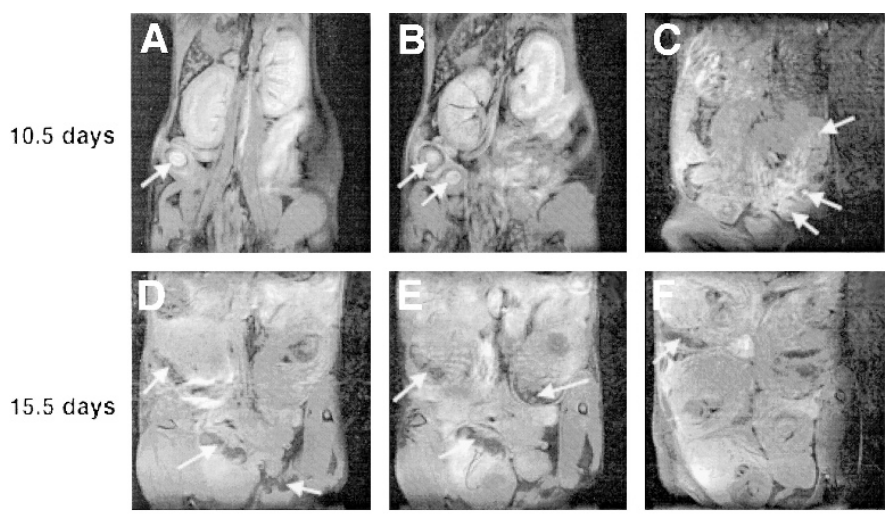

19.5 days
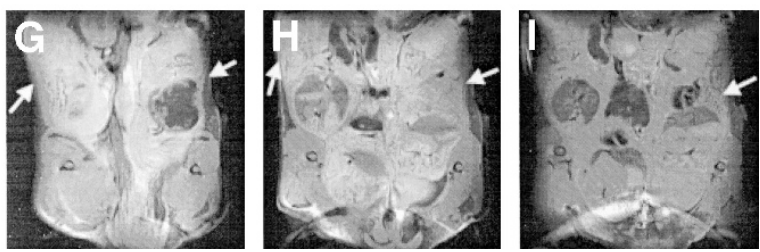

Figure 2. In vivo $\mathrm{MRM}$ images of a gravid $\mathrm{OPN}^{+/+}$mouse. Representative coronal views are shown in $A-I$. A-C show in vivo images at $10.5 \mathrm{~d}$ postcoitus; the white arrows are touching whole embryos in individual gestational sacs. In $D-F$, images at $15.5 \mathrm{~d}$ postcoitus are shown, and the white arrows touch individual placentas. $G-I$ show images at $19.5 \mathrm{~d}$ postcoitus, and the white arrows touch the spinal vertebrae of individual fetuses.

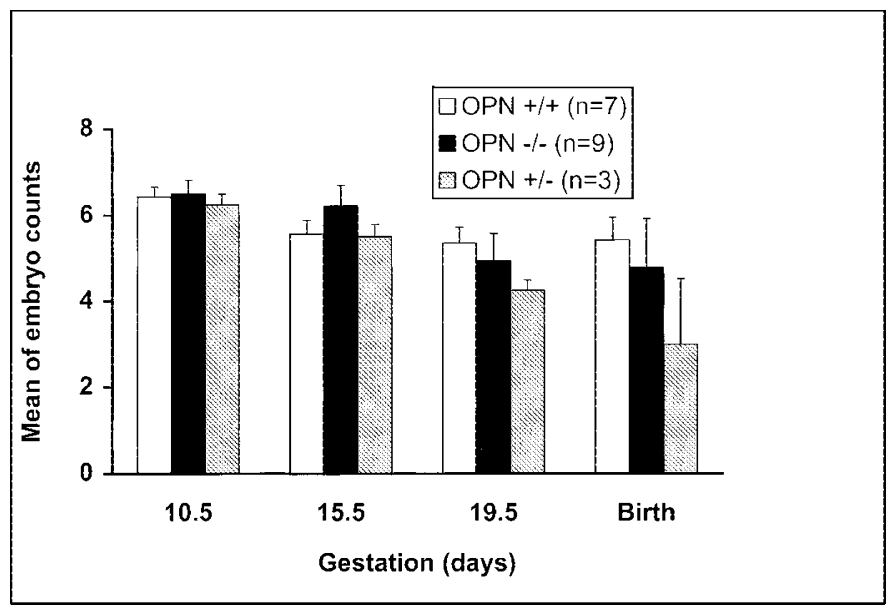

Figure 3. MRM determination of embryo count. MRM images were interpreted independently by two investigators. Because there were no statistically significant differences between the investigators' counts, the values for each observer for each dam on each imaging day were averaged. That average was defined as the embryo count for that dam on that day. The mean embryo count \pm SD for dams of each genotype (white bars: $\mathrm{OPN}^{+/+}$; black bars: $\mathrm{OPN}^{-1-}$; stippled bars: $\left.\mathrm{OPN}^{+/-}\right)$at the four times of measurement $(10.5 \mathrm{~d}, 15.5 \mathrm{~d}$, $19.5 \mathrm{~d}$, and birth) are shown. The embryo counts were analyzed across genotype and gestational day of imaging using a two-way ANOVA.

$(p>0.5)$ or interaction $(p>0.5)$. The significant decrease in embryo count as a result of gestational age occurred between 15.5 and $19.5 \mathrm{~d}(p<0.05)$. There was no difference between embryo counts on days 10.5 and 15.5 or any difference between day 19.5 and the actual number of pups delivered. This suggests that midgestation resorption is not an uncommon event and that once an $\mathrm{OPN}^{-/-}$female is pregnant, she is no more or less likely to undergo midgestation resorption than her wild-type counterparts. Furthermore, the absence of a signifi- cant difference between day 19.5 and birth supports the validity of this technique in determining the true number of embryos.

Embryo size was measured by assuming the embryo shape to be an ellipse. Maximal cross-sectional area was computed as a product of $\pi$ and short-axis and long-axis lengths (area $=$ $\pi \mathrm{ab})$. A representation of this method of measurement is shown in Figure 4. Embryo sizes for $\mathrm{OPN}^{+/+}$and $\mathrm{OPN}^{-/-}$ dams were compared on days 10.5, 15.5, and 19.5 using a two-way ANOVA (Fig. 5). As expected, embryos of both genotypes grew with increasing gestational age $(p<0.001)$. Surprising is that embryos of $\mathrm{OPN}^{-1-}$ dams were significantly smaller than their wild-type counterparts at each gestational age $(p=0.03$; interaction not significant, $p=0.195)$.

Because of concern that the validity of our results could be affected by physical stressors on the dams associated with MRM, we compared litter sizes of our experimental animals with dams that were not imaged. Of the $6 \mathrm{OPN}^{+/+}$dams that underwent MRM, the median (25-75\%) litter size was 6 (4-6.75) versus 5 (3-6) for the 58 pregnant $\mathrm{OPN}^{+/+}$dams that

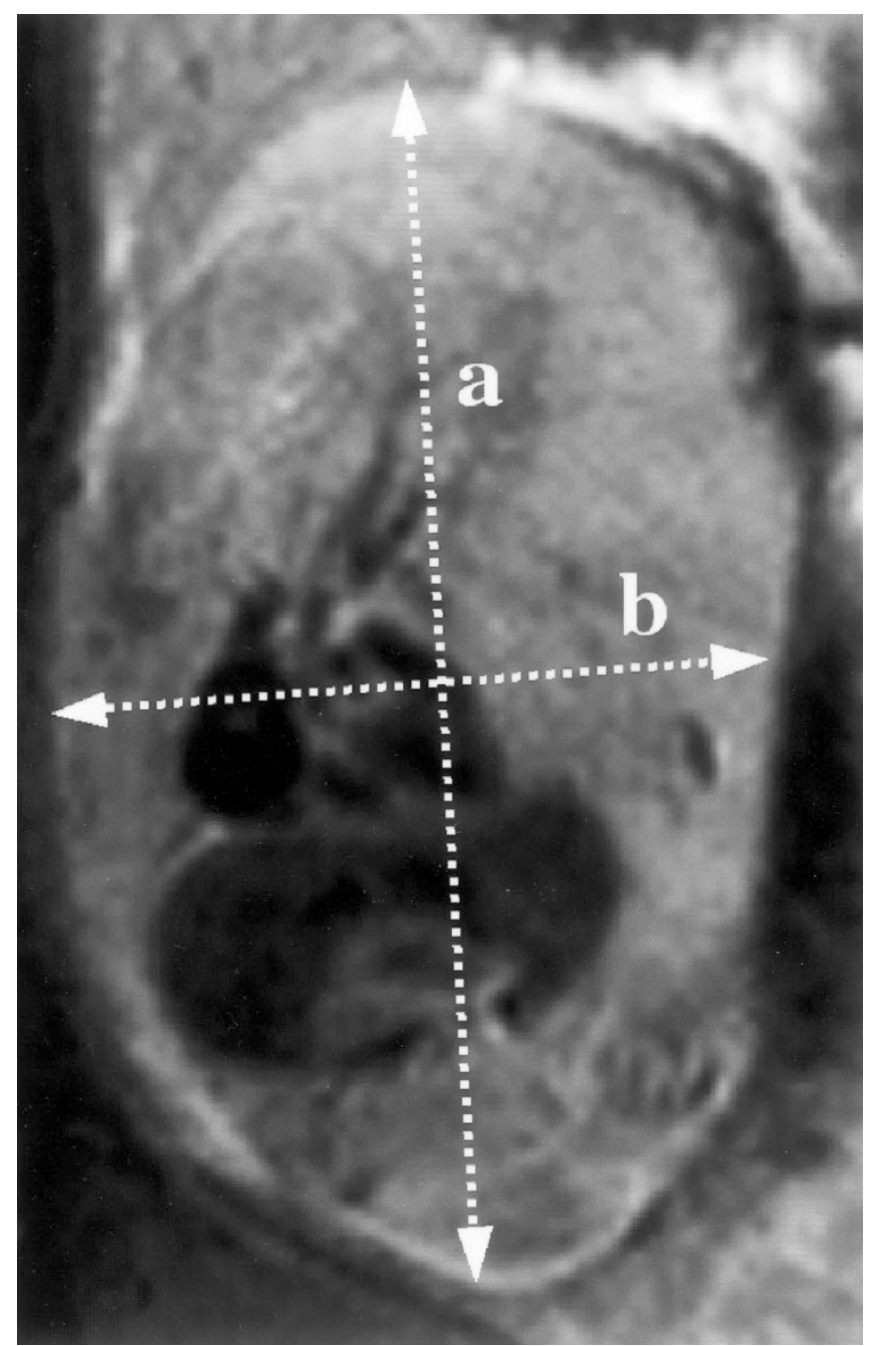

Figure 4. Method of embryo size measurement. A representative 13.5-d embryo in coronal MRM section was used to illustrate the method of size measurement. Measurements were performed assuming embryo shape to be an ellipse. Maximal cross-sectional area was computed as the product of $\pi$ and short-axis $(a)$ and long-axis $(b)$ lengths (area $=\pi \mathrm{ab}$ ). 


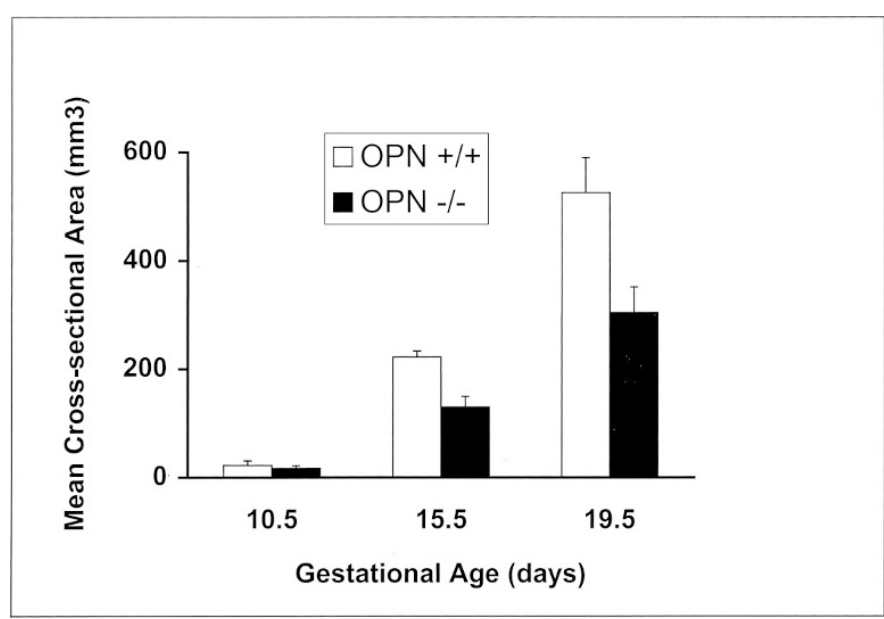

Figure 5. MRM determination of embryo size. Embryo size was determined through calculation of the maximal cross-sectional area. White bars represent the mean of the maximal cross-sectional areas of $\mathrm{OPN}^{+/+}$embryos on days $10.5(n=3), 15.5(n=5)$, and $19.5(n=6)$ of gestation. Black bars similarly represent the mean of the maximal cross-sectional areas of $\mathrm{OPN}^{-1-}$ embryos on days $10.5(n=3), 15.5(n=6)$, and $19.5(n=7)$ of gestation. Error bars indicate SD. Embryo sizes for $\mathrm{OPN}^{+/+}$and $\mathrm{OPN}^{-/-}$were compared across gestational age using a two-way ANOVA.

did not undergo MRM ( $p=0.397)$. Similarly, there was no significant difference in mean litter size between $\mathrm{OPN}^{-1-}$ dams that underwent MRM $(n=8$; mean $\pm \operatorname{SEM}=5.4 \pm 1.1)$ and those that did not $(n=56 ; 5.5 \pm 0.3 ; p=0.91)$.

\section{DISCUSSION}

The noninvasive nature of MRM has made it an exciting method for analysis of the effects of altered gene expression in the placenta and developing embryos of genetically engineered animals. Our data suggest that MRM is a fast, safe, and reliable in vivo technique that can be used to study serially and noninvasively the intact gravid animal. The performance of repeated analyses in the same animal eliminates the need for multiple experimental groups with larger numbers of animals killed at different time points. There has been one previous report of MRM used to investigate noninvasively rat embryo development in vivo (43). Before this, the application of MRM to rodent reproduction was limited to studies of embryonic development using fixed embryos inside (36) or outside the uterus (37-39).

There are many challenges to the use of MRM for the examination of live embryos in situ. These include motion artifact during the maternal cardiorespiratory cycle, limited signal, limited spatial resolution, low inherent contrast, and maternal physiologic instability during image acquisition. In our study, motion artifact was minimized by the use of a long-acting inhalational anesthetic and respiratory gating. The short duration of anesthesia $(\sim 3-3.5 \mathrm{~h})$, in concert with cardiorespiratory monitoring during imaging, resulted in no maternal morbidity or mortality. Ongoing methodologic improvements in signal-to-noise ratio, image resolution, and image acquisition speed will increase the level of detail obtained in future MRM studies.
There is a lack of consensus in the literature about the potential adverse effects of MRM on gravid rodents and their offspring; this discrepancy may be due in part to the extremely long duration exposures that were used in some of the safety studies (40-42), as well as confounding environmental variables, such as physical crowding in the animal restraining device, loud ambient noise, and lowered ambient temperatures in the magnet (41). Despite concern over the potential hazards of repeated exposure of gravid animals to a strong magnetic field, we saw no ill effects in our limited study population. There were no significant differences in mortality for dams or their pups or in litter sizes in the MRM and control groups. That the litter sizes of the study and control dams were equivalent suggests that repeated, short exposures to the magnetic field did not result in an increased rate of fetal resorption above baseline. Examination of pups within the first $48 \mathrm{~h}$ of life revealed no gross abnormalities in either the MRM or control groups.

We have shown MRM to be a reliable and valid method to determine embryo number and size. MRM images were interpreted independently by investigators who were blinded to each other's observations. There were no statistically significant differences between the two investigators' counts, which suggests that the counting of embryos was internally consistent. This demonstration of internal consistency is critical in determining the utility of MRM as a means for prenatal monitoring of embryos, particularly in early gestation, as there are many other small structures in the dam (e.g. loops of bowel containing stool) that could potentially be mislabeled as embryos. Our assessment of observer validity concerned the extent to which our investigators' observations accurately reflected true number of embryos. In our study, there were no significant differences between the embryo count per dam on day 19.5 of gestation and the actual litter size, which suggests that the investigators' counting of embryos accurately reflected in utero numbers at the time of imaging.

Although we were not able to demonstrate a significant effect of genotype on mid- or late-gestation embryo resorption, there was a significant effect of genotype on embryo size at all gestational ages. Thus, the $\mathrm{OPN}^{-1-}$ mouse may provide a model for embryonic growth restriction, although the cause of the growth restriction is unclear. During embryogenesis in the wild-type mouse, OPN expression is developmentally regulated, with late-gestation OPN mRNA expression in the calvaria, spine, and long bones, as well as the renal tubules and placenta (16). Rittling et al. (20) showed that a lack of OPN in bony structures had no effect on either the structure or the distribution of cells within these tissues, and Chellaiah et al. (45) demonstrated that femoral lengths are not reduced in $\mathrm{OPN}^{-1-}$ mice; thus, it is unlikely that the smaller size of $\mathrm{OPN}^{-/-}$embryos is due to alterations in skeletal morphometry.

A more plausible hypothesis for the cause of the intrauterine growth restriction may be changes in uteroplacental blood flow as a result of OPN deficiency in the decidua and placenta. Liaw et al. (46) recently showed that loss of OPN alters hemodynamics and arterial mechanics in the aorta and carotid arteries; $\mathrm{OPN}^{-1-}$ mice were observed to have lower systolic blood pressures, greater arterial compliance, and reduced blood flow at similar heart rates when compared with wild-type controls, as well as defective collagen organization within the arterial 
wall. It is not unreasonable to infer that similar findings would apply to other vascular beds in the $\mathrm{OPN}^{-1-}$ mouse, including the placenta. In that case, the intrauterine growth restriction seen in our $\mathrm{OPN}^{-1-}$ embryos could be the result of decreased placental perfusion, either from relative hypoperfusion of the maternal side of the placenta or from decreased blood flow through morphologically abnormal placental vessels.

We further speculate that abnormal placental vascular development contributed to the decreased incidence of pregnancy seen in the $\mathrm{OPN}^{-1-}$ dams in our study. OPN expression in placenta and decidua is confined to the invasive trophoblast and metrial gland cell populations $(16,32,33)$; metrial gland cells are hypothesized to participate in the remodeling of the uterine stroma and blood vessels that permits growth of the embryo and development of the network of maternal blood sinuses (47). Thus, local alterations in OPN expression could have a tremendous impact on the ability of the conceptus to implant and to develop a life-sustaining blood supply.

\section{REFERENCES}

1. Bayless KJ, Meininger GA, Scholtz JM, Davis GE 1998 Osteopontin is a ligand for the alpha4 beta1 integrin. J Cell Sci 111:1165-1174

2. Denda S, Reichardt LF, Muller U 1998 Identification of osteopontin as a novel ligand for the integrin $\alpha 8 \beta 1$ and potential roles for this integrin-ligand interaction in kidney morphogenesis. Mol Biol Cell 9:1425-1435

3. Liaw L, Lindner V, Schwartz SM, Chambers AF, Giachelli CM 1995 Osteopontin and beta 3 integrin are coordinately expressed in regenerating endothelium in vivo and stimulate Arg-Gly-Asp-dependent endothelial migration in vitro. Circ Res 77:665-672

4. O’Regan AW, Chupp GL, Lowry JA, Goetschkes M, Mulligan N, Berman JS 1999 Osteopontin is associated with $\mathrm{T}$ cells in sarcoid granulomas and has $\mathrm{T}$ cell adhesive and cytokine-like properties in vitro. J Immunol 162:1024-1031

5. Denhardt DT, Lopez CA, Rollo EE, Hwang SM, An XR, Walther SE 1995 Osteopontin-induced modifications of cellular functions. Ann N Y Acad Sci 760:127-142

6. Scatena M, Almeida M, Chaisson ML, Nicosia RF, Giachelli CM 1998 NF- $\kappa$ B mediates $\alpha \mathrm{v} \beta 3$ integrin-induced endothelial cell survival. J Cell Biol 141:1083-1093

7. Crawford HC, Matrisian LM, Liaw L 1998 Distinct roles of osteopontin in host defense activity and tumor survival during squamous cell carcinoma progression in vivo. Cancer Res 58:5206-5215

8. Weintraub AS, Schnapp LM, Lin X, Taubman MB 2000 Osteopontin deficiency in rat vascular smooth muscle cells is associated with an inability to adhere to collagen and increased apoptosis. Lab Invest 80:1603-1615

9. Patarca R, Saavedra RA, Cantor H 1993 Molecular and cellular basis of genetic resistance to bacterial infection: the role of the early T-lymphocyte activation-1/ osteopontin gene. Crit Rev Immunol 13:225-246

10. O'Regan A, Berman JS 2000 Osteopontin: a key cytokine in cell-mediated and granulomatous inflammation. Int J Exp Pathol 81:373-390

11. Nau GJ, Liaw L, Chupp GL, Berman JS, Hogan BL, Young RA 1997 A chemoattractant cytokine associated with granulomas in tuberculosis and silicosis. Proc Natl Acad Sci U S A 94:6414-6419

12. Singh RP, Patarca R, Schwartz J, Singh P, Cantor H 1990 Definition of a specific interaction between the early $\mathrm{T}$ lymphocyte activation 1 (Eta-1) protein and murine macrophages in vitro and its effect upon macrophages in vivo. J Exp Med 171:1931-1942

13. Ashkar S, Weber GF, Panoutsakopoulou V, Sanchirico ME, Jansson M, Zawaideh S, Rittling SR, Denhardt DT, Glimcher MJ, Cantor, H 2000 Eta-1 (osteopontin): an early component of type 1 (cell-mediated) immunity. Science 287:860-864

14. Oldberg A, Franzen A, Heinegard D 1986 Cloning and sequence analysis of rat bone sialoprotein (osteopontin) cDNA reveals an Arg-Gly-Asp cell-binding sequence. Proc Natl Acad Sci U S A 83:8819-8823

15. Brown LF, Berse B, Van de Water L, Papadopoulos-Sergiou A, Peruzzi CA, Manseau EJ, Dvorak HF, Senger DR 1992 Expression and distribution of osteopontin in human tissues: widespread association with luminal epithelial surfaces. Mol Biol Cell 3:1169-1180

16. Nomura S, Wills AJ, Edwards DR, Heath JK, Hogan BL 1988 Developmental expression of 2ar (osteopontin) and SPARC (osteonectin) RNA as revealed by in situ hybridization. J Cell Biol 106:441-450

17. Murry CE, Giachelli CM, Schwartz SM, Vracko R 1994 Macrophages express osteopontin during repair of myocardial necrosis. Am J Pathol 145:1450-1462

18. O'Brien ER, Garvin MR, Stewart DK, Hinohara T, Simpson JB, Schwartz SM, Giachelli CM 1994 Osteopontin is synthesized by macrophage, smooth muscle, and endothelial cells in primary and restenotic human coronary atherosclerotic plaques. Arterioscler Thromb 14:1648-1656

19. Giachelli CM, Lombardi D, Johnson RJ, Murry CE, Almeida M 1998 Evidence for a role of osteopontin in macrophage infiltration in response to pathological stimuli in vivo. Am J Pathol 152:353-358
20. Rittling SR, Matsumoto HN, McKee MD, Nanci A, An XR, Novick KE, Kowalski AJ, Noda M, Denhardt DT 1998 Mice lacking osteopontin show normal development and bone structure but display altered osteoclast formation in vitro. J Bone Miner Res 13:1101-1111

21. Nau GJ, Liaw L, Chupp GL, Berman JS, Hogan BLM, Young RA 1999 Attenuated host response against Mycobacterium bovis (BCG) infection in mice lacking osteopontin. Infect Immunol 67:4223-4230

22. O'Regan AW, Hayden JM, Body S, Liaw L, Mulligan N, Goestschkes M, Berman JS 2001 Abnormal pulmonary granuloma formation in osteopontin-deficient mice. Am J Respir Crit Care Med 164:2243-2247

23. Giachelli CM, Pichler R, Lombardi D, Denhardt DT, Alpers CE, Schwartz SM, Johnson RJ 1994 Osteopontin expression in angiotensin II-induced tubulointerstitial nephritis. Kidney Int 45:515-524

24. Chambers AF, Wilson SM, Kerkvliet N, O’Malley FP, Harris JF, Casson AG 1996 Osteopontin expression in lung cancer. Lung Cancer 15:311-323

25. Chabas D, Baranzini SE, Mitchell D, Bernard CC, Rittling SR, Denhardt DT, Sobel RA, Lock C, Karpuj M, Pedotti R, Heller R, Oksenberg JR, Steinman L 2001 The influence of the proinflammatory cytokine, osteopontin, on autoimmune demyelinating disease. Science 294:1737-1735

26. Jansson M, Panoutsakopoulou V, Baker J, Klein L, Kantor H 2002 Attenuated experimental autoimmune encephalomyelitis in Eta1/Osteopontin-deficient mice. J Immunol 168:2096-2099

27. Young MF, Kerr JM, Termine JD, Wewer UM, Wang MG, McBride OW, Fisher LW 1990 cDNA cloning, mRNA distribution and heterogeneity, chromosomal location, and RFLP analysis of human osteopontin (OPN). Genomics 7:491-502

28. Fazleabas AT, Bell SC, Fleming S, Sun J, Lessey BA 1997 Distribution of integrins and the extracellular matrix proteins in the baboon endometrium during the menstrual cycle and early pregnancy. Biol Reprod 56:348-356

29. Garlow JE, Ka H, Johnson GA, Burgardt RC, Jaeger LA, Bazer FW 2002 Analysis of osteopontin at the maternal-placental interface in pigs. Biol Reprod 66:718-725

30. Johnson GA, Bazer FW, Jaeger LA, Ka H, Garlow JE, Pfarrer C, Spencer TE, Burgardt RC 2001 Muc-1, integrin, and osteopontin expression during the implantation cascade in sheep. Biol Reprod 65:820-828

31. Apparao KBC, Murray MJ, Fritz MA, Meyer WR, Chambers AF, Truong PR, Lessey BA 2001 Osteopontin and its receptor $\alpha \mathrm{v} \beta 3$ integrin are coexpressed in the human endometrium during the menstrual cycle but regulated differently. J Clin Endocrinol Metab 86:4991-5000

32. Omigbodun A, Ziolkiewicz P, Tessler C, Hoyer JR, Coutifaris C 1997 Progesterone regulates osteopontin expression in human trophoblasts: a model of paracrine control in the placenta. Endocrinology 138:4308-4315

33. Gabinskaya T, Salafia CM, Gulle VE, Holzman IR, Weintraub AS 1998 Gestational age-dependent extravillous cytotrophoblast osteopontin immunolocalization differentiates between normal and preeclamptic pregnancies. Am J Reprod Immunol 40:339346

34. Fayad ZA, Fallon JT, Shinnar M, Wehrli S, Dansky HM, Poon M, Badimon JJ, Charlton SA, Fisher EA, Breslow JL, Fuster V 1998 Noninvasive in vivo highresolution magnetic resonance imaging of atherosclerotic lesions in genetically engineered mice. Circulation 98:1541-1547

35. Johnson GA, Benveniste H, Black RD, Hedlund LW, Maronpot RR, Smith BR 1993 Histology by magnetic resonance microscopy. Magn Reson Q 9:1-30

36. Schneider JE, Bamforth SD, Grieve SM, Clarke K, Bhattacharya S, Neubauer S 2003 High-resolution, high-throughput magnetic resonance imaging of mouse embryonic anatomy using a fast gradient-echo sequence. MAGMA 16:43-51

37. Smith BR, Linney E, Huff DS, Johnson GA 1996 Magnetic resonance microscopy of embryos. Comput Med Imaging Graph 20:483-490

38. Orita J, Sato E, Saburi S, Nishida T, Toyada Y 1996 Magnetic resonance imaging of the internal structures of the mouse fetus. Exp Anim 45:171-174

39. Smith BR 2001 Magnetic resonance microscopy in cardiac development. Microsc Res Tech 52:323-330

40. Heinrichs WL, Fong P, Flannery M, Heinrichs SC, Crooks LE, Spindle A, Pedersen RA 1988 Midgestational exposure of pregnant BALB/c mice to magnetic resonance imaging conditions. Magn Reson Imaging 6:305-313

41. Carnes KI, Magin RL 1996 Effects of in utero exposure to 4.7T MR imaging conditions on fetal growth and testicular development in the mouse. Magn Reson Imaging 14:263-274

42. Magin RL, Lee JK, Klintsova A, Carnes KI, Dunn F 2000 Biological effects of long duration, high-field (4T) MRI on growth and development in the mouse. J Magn Reson Imaging 12:140-149

43. Smith BR, Shattuck MD, Hedlund LW, Johnson GA 1998 Time-course imaging of rat embryos in utero with magnetic resonance microscopy. Magn Reson Med 39:673677

44. Milliken GA, Johnson DE 1984 Analysis of Messy Data. Van Nostrand Reinhold Company, New York, pp 326-337

45. Chellaiah MA, Kizer N, Biswas R, Alvarez U, Strauss-Schoenberger J, Rifas L, Rittling SR, Denhardt DT, Hruska KA 2003 Osteopontin deficiency produces osteoclast dysfunction due to reduced CD44 surface expression. Mol Biol Cell 14:173189

46. Myers DL, Harmon KJ, Lindner V, Liaw L 2003 Alterations of arterial physiology in osteopontin-null mice. Arterioscler Thromb Vasc Biol 23:1021-1028

47. Waterhouse P, Parhar RS, Guo X, Lala PK, Denhardt DT 1992 Regulated temporal and spatial expression of the calcium-binding proteins calcyclin and OPN (osteopontin) in mouse tissues during pregnancy. Mol Reprod Dev 32:315-323 